\title{
Listening for deterioration and failure: towards smart geotechnical infrastructure
}

Alister Smith MEng, PhD, FGS, GMICE, FHEA

EPSRC Fellow and Lecturer in Civil Engineering, School of Architecture, Building and Civil Engineering, Loughborough University, Loughborough, UK (corresponding author: a.smith10@|boro.ac.uk) (Orcid:0000-0003-3363-300X)
Neil Dixon BSC, PhD, FGS

Professor of Geotechnical Engineering, School of Architecture, Building and Civil Engineering, Loughborough University, Loughborough, UK

Global change is accelerating the rate of deterioration of geotechnical infrastructure systems. There is an urgent need for monitoring strategies that can be used to assess existing, ageing infrastructure through retrofitting sensors at discrete locations to detect and provide early warning of limit state failures. This paper describes a novel approach for smart geotechnical infrastructure that 'listens' to acoustic emission generated by geotechnical asset deterioration and failure. Acoustic emission rates generated by geotechnical systems have been proven to be proportional to deformation rates. It is becoming an accepted monitoring technology for geotechnical applications; however, challenges still exist to develop widely applicable interpretation strategies. This paper places acoustic emission geotechnical monitoring in a smart infrastructure context and presents the key factors influencing acoustic emission propagation and attenuation in buried structural elements; techniques for quantifying parameters; and interpretation frameworks for extracting information and knowledge on the deformation and strength behaviour of geotechnical infrastructure systems. Acoustic emission interpretation strategies for exemplar applications (e.g. slopes, pile foundations and buried pipelines) are developed and demonstrated through element- and large-scale experiments and field trials.

\section{Notation}

A acoustic emission (AE) waveform amplitude

$b$-value measure of the proportion of low- and highmagnitude events in an AE waveform

$m \quad$ log-scale measure of the AE magnitude

$N \quad$ number of $\mathrm{AE}$ events with a magnitude greater than $m$

\section{Introduction}

Infrastructure systems are fundamental for the functioning of society. Road and rail transport infrastructure, water distribution networks and power grids can be characterised as long-linear assets. Management and maintenance require understanding of the behaviour of these infrastructure systems and detection of changes that occur along their length due to complex deterioration mechanisms. Although globally there are ambitious programmes for delivering new infrastructure to improve the quality of life (WHO and Unicef JMP, 2015), many societies will rely for the foreseeable future on existing infrastructure. Much of this was designed and constructed many decades ago to meet very different user requirements (e.g. the UK railways constructed in the nineteenth century). Continued performance of this ageing infrastructure is critical to the quality of life of individuals and prosperity of nations. Wholesale replacement of heavily used infrastructure is both prohibitively expensive and impractical. Maintaining infrastructure assets requires a greater level of information than what is currently available to deliver improved decisions. This need is driving efforts to produce 'smart infrastructure' (ICE, 2016).

Rapid technological advances are being made in geotechnical condition monitoring. Distributed optical fibre strain sensing has been developed with applications demonstrated in a range of geotechnical assets, including tunnel linings (e.g. Cheung et al., 2010), pile foundations (e.g. Pelecanos et al., 2017) and retaining walls (Mohamad et al., 2011). Developments have also been made employing in-place inclinometer systems (e.g. ShapeAccelArray (Macciotta et al., 2016)), wireless sensor networks (e.g. Hoult et al., 2009), photogrammetry (e.g. Alhaddad et al., 2018; Wheeler et al., 2016) and electrical resistivity tomography geophysics (e.g. Uhlemann et al., 2017).

Smart infrastructure can be defined as employing technologies such as connected sensors and big-data analytics integrated with physical infrastructure to deliver real-time monitoring of performance and state, leading to better decision-making and enhanced service (Weiss, 2009). Smart infrastructure has the potential to increase safety by implementing early-warning systems in critical operations and to allow a move from scheduled and reactive to predictive and proactive maintenance schemes. However, to realise delivery of smart infrastructure, three main challenges must be resolved as defined by Hartmann (2018). These challenges are driving extensive research worldwide.

- First, there is a need to deliver 'state awareness' (ICE, 2016) whereby sensors measure the real-time behaviour of a diverse range of infrastructure systems in response to environmental drivers (e.g. loading and weather) (Soga and Schooling, 2016).

- Second, data analytics are needed to process and extract information and useable knowledge from the big data generated by sensors (e.g. Bennetts et al., 2018; Lau et al., 2018). 
Smart Infrastructure and Construction

Volume 171 Issue 4
Listening for deterioration and failure:

towards smart geotechnical

infrastructure

Smith and Dixon
- Third, decision-making methods need to be implemented that can combine information and knowledge extracted from multiple data sources to categorise asset states, predict future behaviour and hence provide early warning of failure and inform timing of interventions (e.g. maintenance or renewal).

A further overarching challenge in delivering smart infrastructure is the need to instrument both new and existing assets. While incorporating sensor systems in new-build infrastructure is achievable with minimal disruption and at a relatively low cost (Soga and Schooling, 2016), many of the existing technologies cannot easily be retrofitted along the many thousands of kilometres of existing, ageing infrastructure (e.g. buried pipes and earthwork slopes).

This paper addresses the need for an approach that can be used to retrofit sensors on existing infrastructure, in addition to new build, and which can monitor the state of an asset and detect deterioration mechanisms and their rate of change (ICE, 2016) so that early warnings of limit states can be delivered. The focus is on geotechnical systems in infrastructure (e.g. buried pipes, foundations). The approach uses the acoustic emission (AE) generated by deformation of assets to 'listen' for deterioration and failure. Figure 1 shows an illustration of the sensing concept applied to a buried pipeline. Differential ground movement causes soil deformation and relative deformation between the soil and pipe wall, which generates high-frequency noise (i.e. AE). This $\mathrm{AE}$ is transmitted into the pipeline where it propagates as guided waves to distributed monitoring sensors, which interpret the $\mathrm{AE}$ and send warnings to decision makers by way of telemetry.

All infrastructure is constructed in/on the ground. Stress cycles and deformation of the soil/structure system can lead to deterioration of asset performance. Global change is accelerating the rate of deterioration of geotechnical infrastructure systems through, for example, weather cycles with more significant extremes and increasing magnitude and increased frequency of user loading. This novel sensing approach employs distributed monitoring locations on asset elements (e.g. pipes, piles and retaining walls). The assets then become an integral component of the measurement system as shown in Figure 1, allowing continuous measurements to be made along extended lengths of asset (e.g. hundreds of metres per sensor), which offers significant benefits over conventional monitoring approaches that provide localised information on deformations at discrete time intervals.

The paper places AE geotechnical monitoring in a smart infrastructure context, introduces the $\mathrm{AE}$ sensing approach and presents the key factors influencing $\mathrm{AE}$ propagation and attenuation in buried structural elements; techniques for quantifying $\mathrm{AE}$ parameters; and $\mathrm{AE}$ interpretation frameworks for extracting information and knowledge on the deformation and strength behaviour of geotechnical infrastructure systems. AE interpretation strategies for exemplar applications (e.g. slopes, pile foundations and buried pipelines) are developed and demonstrated through element- and large-scale experiments and field trials.

\section{AE monitoring of geotechnical infrastructure systems}

$\mathrm{AE}$ is becoming an accepted monitoring technology for geotechnical applications (e.g. Berg et al., 2018; Dixon et al., 2015a, 2015b; Mao et al., 2018a, 2018b; Smith et al., 2014, 2019a); however, challenges still exist to develop widely applicable AE interpretation strategies. AE are relatively highfrequency (i.e. typically non-audible) elastic stress waves that propagate through materials surrounding the generation source. $\mathrm{AE}$ is generated when a material undergoes irreversible changes in its internal structure - for example, as a result of crack formation or plastic deformation due to ageing, temperature gradients or external mechanical forces. AE has had successful application in a range of domains, typically to detect, locate and characterise damage - for example, structural health monitoring, quality control, system feedback and process monitoring (Beatie, 1983; Grosse and Ohtsu, 2008).

Successful application of AE monitoring in geotechnical engineering has been limited until recently because a series of key challenges needed to be addressed (Smith, 2015)

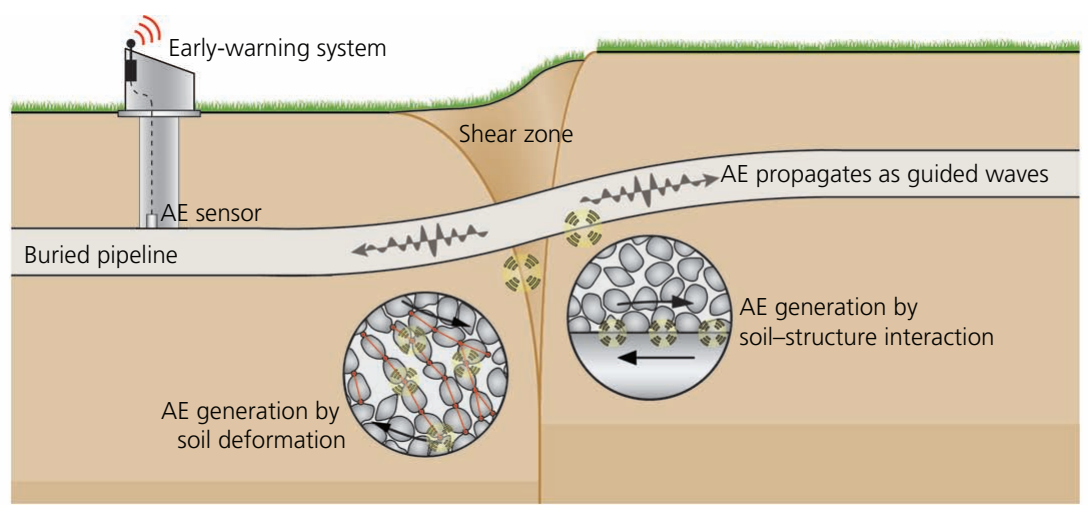

Figure 1. Illustration of the AE monitoring concept applied to buried pipelines 
- the high level of attenuation that soil-generated AE experiences as it propagates through soil bodies in three dimensions

v the need to filter out background noise (e.g. generated by environmental noise, construction activity and traffic)

v the requirement for unitary portable technology that can monitor AE continuously for long durations in the field environment

- the need to develop strategies for interpreting and quantifying mechanical and hydromechanical behaviour from the measured AE.

An important difference between conventional applications for $\mathrm{AE}$ and those in geotechnical engineering is the distinction between transient and continuous AE. Mechanisms such as crack nucleation release AE rapidly over a short, defined time period, which is referred to as a transient event. In contrast, soil bodies are made up of large numbers of particles and each particle-scale interaction generates a transient event, which combine and form continuous $\mathrm{AE}$.

Proportions of the energy dissipated during deformation of, and seepage of fluid through, soils are converted to heat and sound. The high-frequency $(>10 \mathrm{kHz})$ component of this sound energy is AE. Dissipated energy in soil bodies and soil/structure systems predominantly occurs due to friction, damping (i.e. particle rearrangement) and damage (i.e. degradation at particle asperities and crushing). Hence, $\mathrm{AE}$ sensing is a valuable technique for monitoring energy dissipation in geotechnical systems due to, for example, stress changes and deformation. Increasing $\mathrm{AE}$ generation rates (i.e. increasing energy dissipation within the geotechnical system per unit time) can be used to detect, quantify and interpret accelerating deformation behaviour that accompanies progressive ground failure processes for use in early warning by decision makers.

Fundamental laboratory studies on the AE behaviour of soils carried out in the 1970s, 1980s and 1990s (e.g. Koerner et al., 1976, 1978, 1981, 1984; Garga and Chichibu, 1990; Mitchell and Romeril, 1984; Shiotani and Ohtsu, 1999; Tanimoto and Nakamura, 1981; Tanimoto and Tanaka, 1986) led to the following qualitative conclusions: well-graded soils generate more AE than uniformly graded soils; angular particles generate more AE than rounded particles; AE amplitude increases with particle size; higher imposed stresses generates greater AE activity; and $\mathrm{AE}$ activity increases with imposed strain rate. Koerner et al. (1981) proposed the following qualitative guide for interpretation of $\mathrm{AE}$ generated from soils deforming against a steel structural element: $(a)$ no AE indicates stability; $(b)$ moderate levels of AE indicate marginal stability; and (c) high levels of AE indicate that the geotechnical system is unstable.

The purpose of $\mathrm{AE}$ research in geotechnical engineering over the past 60 years has been to quantify links between measured $\mathrm{AE}$ and strength and deformation behaviour to enable interpretation of the field performance of geotechnical infrastructure systems, with a focus on slope stability monitoring. Recent advances have been made in the quantitative interpretation of mechanical behaviour from $\mathrm{AE}$ measurements using laboratory and field experiments. A significant recent advance has been quantification of relationships between measured $\mathrm{AE}$ and slope deformation behaviour, enabling early warning of accelerating slope movements and failure (Berg et al., 2018; Dixon et al., 2015a, 2015b, 2018; Michlmayr et al., 2017; Smith and Dixon, 2015; Smith et al., 2014, 2017a). Relationships between measured AE and pile load-displacement behaviour are being developed (Mao et al., 2015, 2016, 2018a, 2018b). AE monitoring is also being used to quantify the deformation behaviour experienced by buried pipelines subjected to differential ground movements (Smith et al., 2019a, 2019b, 2019c).

\section{AE propagation and waveguides}

$\mathrm{AE}$ attenuates significantly as it propagates in three dimensions through a soil body and hence low-attenuation propagation paths (i.e. waveguides) are required to measure $\mathrm{AE}$ generated at depth or large distances away from the monitoring sensors. Steel suffers significantly less attenuation than soil, by orders of magnitude, and therefore, steel elements are typically employed as waveguides. For example, AE sensors can be coupled to preexisting structural elements, such as the outside wall of piles or pipelines, to measure soil-structure interaction-generated $\mathrm{AE}$ associated with ground movements along a length of the structure. In slope-stability-monitoring applications, exploiting pre-existing structural elements is not always possible, and so waveguide systems must be designed and installed. Figure 2 shows the active waveguide system that is used for slope stability monitoring where the granular backfill generates $\mathrm{AE}$ in response to slope movements.

AE transmitted into structural elements propagate as guided waves with a range of mode types (e.g. plane longitudinal, shear

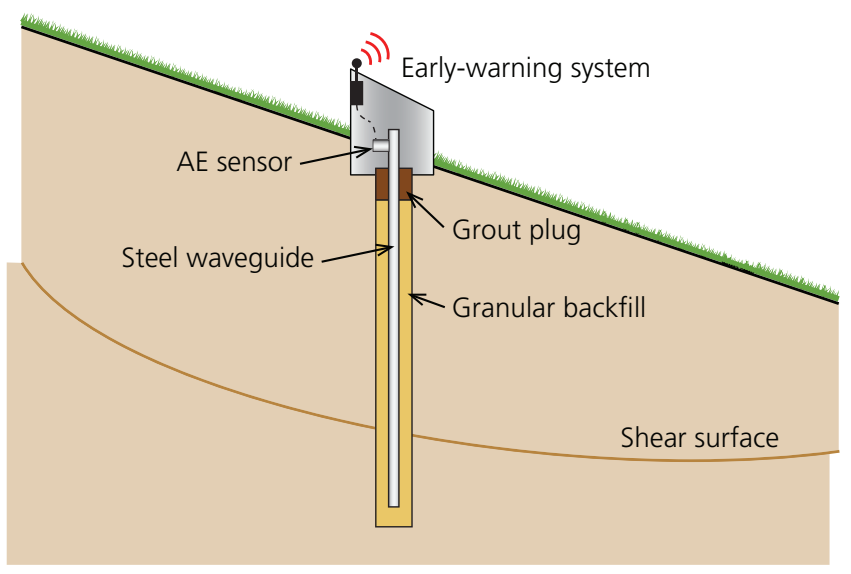

Figure 2. Illustration of the active waveguide system used for $A E$ monitoring of slope stability 
Smart Infrastructure and Construction

Volume 171 Issue 4
Listening for deterioration and failure:

towards smart geotechnical

infrastructure

Smith and Dixon and torsional and symmetric and asymmetric Lamb), which exhibit different propagation and attenuation characteristics (Heather-Smith et al., 2018; Smith et al., 2017b). The scale of the wavelength compared with the cross-sectional geometry (i.e. pipe wall thickness) governs which mode types propagate (Maji et al., 1997; Smith et al., 2017b). Attenuation of elastic stress waves occurs in materials due to mechanisms such as geometrical spreading, internal friction, scattering, diffraction and dispersion.

Buried structural elements will have both internal and external environments and, in the case of buried pipelines, joints at regular spacings. Boundaries with discontinuities in acoustic impedance increase attenuation (i.e. loss of AE energy) - for example, the changes in cross-section at joints and differences in material properties at interfaces with the internal (e.g. water, oil and gas) and external environments (i.e. soil). A framework for quantifying the magnitude of attenuation experienced by $\mathrm{AE}$ in buried structural elements has been developed using numerical simulations and large-scale experiments (e.g. Heather-Smith et al., 2018; Smith et al., 2017b). Example AE attenuation coefficients obtained experimentally by Smith et al. (2017b) for air-steel pipe-air and air-steel pipe-soil tri-layer systems in the $20-30 \mathrm{kHz}$ frequency range were 0.2 and $2.8 \mathrm{~dB} / \mathrm{m}$, respectively, which means that $\mathrm{AE}$ can propagate many tens or even hundreds of metres from the generation source to the measurement point. Attenuation in steel pipes is on the order of 100000 times lower than in soils. Development of an attenuation framework is enabling sensor spacings to be selected for a range of buried infrastructure applications. In addition, it also enables methodologies to be developed for source localisation by using the difference in arrival times between modes with known velocities to locate the position of the originating source along the length of the asset.

Source localisation methodologies are also being developed for AE propagating through soil bodies (e.g. Koseki, 2019; Mao et al., 2019). However, while these advances have a role in element-scale laboratory testing, the significant levels of $\mathrm{AE}$ attenuation in soil bodies highlighted earlier mean that these approaches are impractical for field monitoring.

This body of research has identified several key variables that influence $\mathrm{AE}$ attenuation in buried structural elements. The attenuation magnitude is a function of the cross-sectional geometry, the properties of the joints (e.g. threaded or welded), the frequency content of the AE, the propagating mode type(s) and the density, Young's modulus and Poisson's ratio of the structural element, the internal environment and the external environment. In addition, consideration should be given to the depth-dependent nature of density, Young's modulus and Poisson's ratio in the external environment (i.e. soil).

\section{AE measurement and quantification}

The key, generic components of an AE measurement system include a piezoelectric transducer (e.g. the Mistras R $3 \alpha$ sensor is widely used in geotechnical monitoring, which is sensitive over the frequency range $0-100 \mathrm{kHz}$ and has a resonant frequency of $30 \mathrm{kHz}$ ) to convert the mechanical AE stress waves to voltage signals that can be conditioned and processed; bandpass filters and amplifiers to improve the signal-to-noise ratio; and analogueto-digital converters to enable digital reconstruction of the waveform for storage and analysis. Filtering is an essential part of the $\mathrm{AE}$ measurement sequence. By removing low-frequency signals - for example, those below $20 \mathrm{kHz}$ - false alarms are avoided, as extraneous noise is removed from the measurements (e.g. traffic and construction activity). Extensive field trials of slope stability monitoring using an $\mathrm{AE}$ measurement system that filters outside of the $20-30 \mathrm{kHz}$ range have demonstrated that extraneous noise is removed (Dixon et al., 2015a, 2015b, 2018; Smith et al., 2014) and false alarms are not generated.

Figure 3 shows a series of time-domain methods for $\mathrm{AE}$ parameter quantification. Ring-down counts (RDCs) per unit time are the number of times that the $\mathrm{AE}$ waveform crosses a programmable threshold level within a predefined time interval and are a measure of signal energy. RDCs are widely used for continuous AE monitoring in geotechnical engineering because they can be computed in the hardware, removing the need for digital reconstruction of the full waveform and hence significantly reducing the processing and storage requirements for batteryoperated field-based measurement devices. Moreover, monitoring RDCs improves extraneous noise removal; any noise (e.g. electronic) below the pre-set threshold level is ignored.

The area under the rectified $\mathrm{AE}$ waveform is referred to as the signal energy, and the root-mean square is a measure of the mean amplitude. Another useful AE parameter is the $b$-value, which can be obtained from the full AE waveform data (Pollock, 1973) and is a convenient way to describe the amplitude distribution in a single value. When the $\mathrm{AE}$ waveform is dominated by lowamplitude events, the $b$-value is large. As the proportion of higher amplitude events increases, indicating an increase in energy, the $b$-value reduces. The $b$-value is computed at intervals using the following equations

1. $\log N=c-b m$

2. $m=\log A$

where $A$ is the amplitude; $m$ is a log-scale measure termed 'magnitude'; $N$ is the number of $\mathrm{AE}$ events with a magnitude greater than $m ; c$ is the point that the $\log N$-against- $m$ relationship intersects the $y$-axis; and the coefficient $b$ ( $b$-value) is the negative slope of the $\log N$-against- $m$ relationship. In addition, frequencydomain parameters are useful where critical mechanisms have characteristic or dominant frequencies (e.g. particle crushing (Section 5)). 


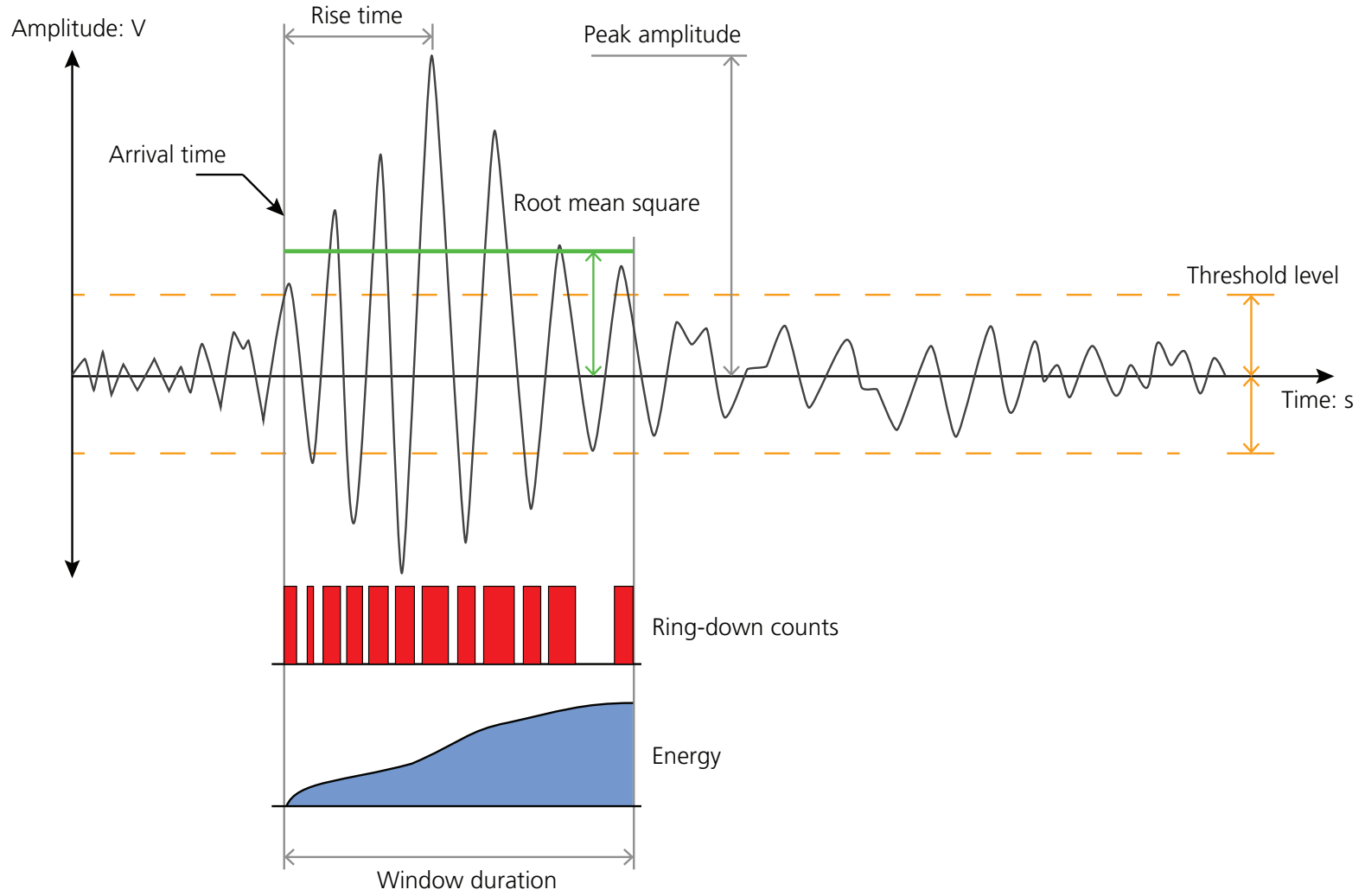

Figure 3. Example AE waveform with a suite of $A E$ quantification parameters superimposed

\section{AE generated by soil bodies and soil/ structure systems}

Programmes of drained triaxial isotropic compression and shearing (axial compression) tests on sands and direct-shear testing of sand/steel plate interfaces (Smith and Dixon, 2019a, 2019b; Smith et al., 2019b) have shown that AE generation is governed by the stress level, mobilised shear strength, strain (or deformation) rate and fabric evolution (e.g. volume change behaviour). This research has also shown that $\mathrm{AE}$ activity is negligible until the current stress conditions (compression and/or shear) exceed the maximum that the system has experienced in the past; this behaviour is well established in $\mathrm{AE}$ monitoring of materials as the Kaiser effect. Figure 4 shows typical, idealised trends obtained from cycles of load-unload-reload triaxial isotropic compression (i.e. mean effective stress in Figure 4(a)) and shearing phases (deviator stress in Figure $4(\mathrm{~b})$ ) and

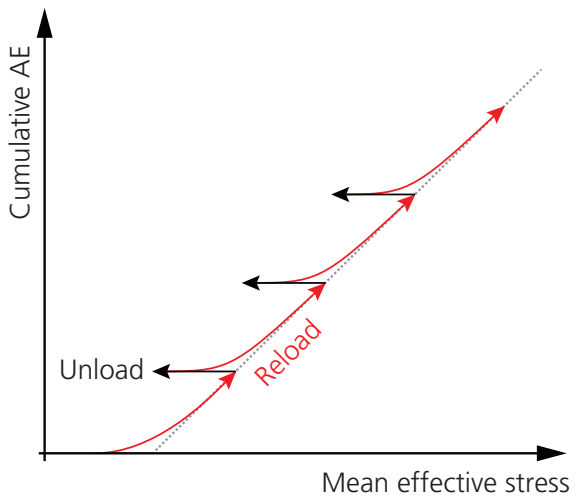

(a)

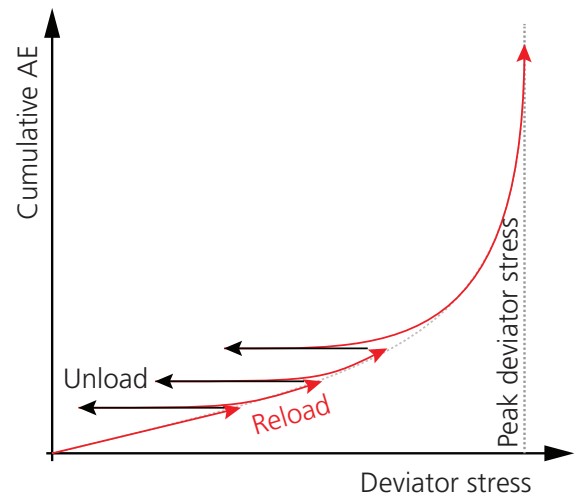

(b)

Figure 4. Illustrative, idealised AE trends from triaxial tests on dense sand (from Smith et al. (2019a, 2019c)): (a) isotropic load-unload-reload cycles of cell pressure; (b) load-unload-reload cycles of deviator stress 
Smart Infrastructure and Construction

Volume 171 Issue 4
Listening for deterioration and failure:

towards smart geotechnical

infrastructure

Smith and Dixon

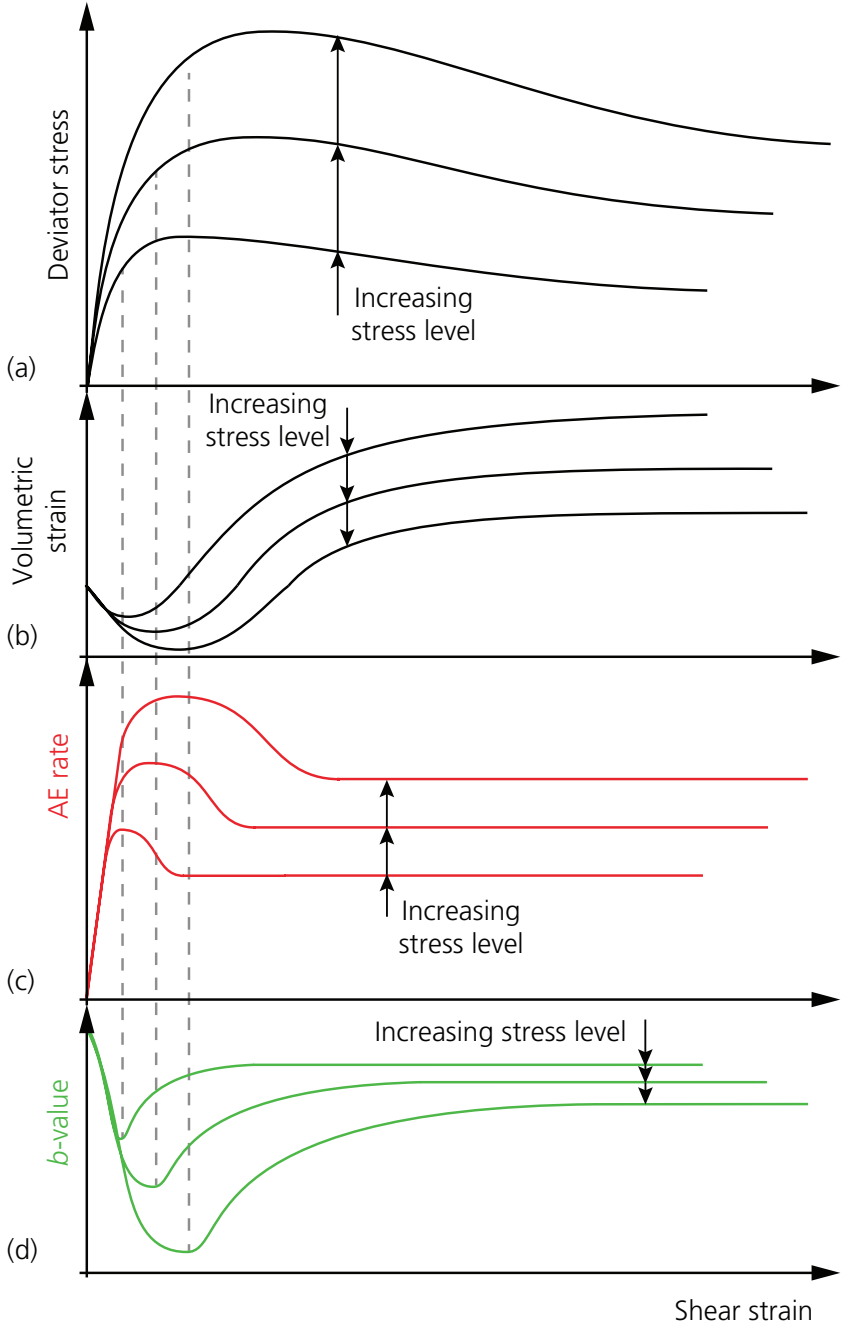

Figure 5. Illustrative, idealised AE trends from triaxial shearing tests on dense sand (from Smith et al. (2019a, 2019c)):

(a) deviator stress plotted against shear strain; (b) volumetric strain plotted against shear strain; (c) AE rate plotted against shear strain; (d) $b$-value plotted against shear strain demonstrates that $\mathrm{AE}$ can be used to detect when previous maximum stress states have been exceeded.

Deviator stress is the difference between the major and minor principal stresses acting on a soil body, which causes shear (or distortional) strain. The mean effective stress represents the average stress carried by the soil solids and causes volumetric strain.

Figure 5 presents exemplar, idealised trends obtained from a series of triaxial shearing tests performed by Smith and Dixon (2019a) on dense Leighton Buzzard sand. Figure 5 shows that AE rates generated by soil bodies in shearing increase with the stress level (e.g. analogous to different asset burial depths) and are proportional to the mobilised shear strength. Figure 5 also shows that $\mathrm{AE}$ measurements can be used to detect peak shear strength mobilisation. Exemplar trends derived from direct-shear tests of sand/steel plate interfaces performed by Smith et al. (2019b) are presented in Figure 6, which shows that $\mathrm{AE}$ rate and $b$-value measurements are proportional to the relative soil/structure shearing velocity, and hence, $\mathrm{AE}$ monitoring can be used to quantify the accelerating deformation behaviour in such geotechnical systems.

This body of research has identified several key variables that influence AE generation in soil bodies and soil/structure systems. For example, AE generation from deformation of a buried linear, cylindrical structural element (e.g. pipe or pile) is influenced by pipe circumference, soil properties and state, pipe interface surface properties, effective normal stress, mobilised shear strength and strain rate.

Research has demonstrated that deforming soils generate significant $\mathrm{AE}$ within the frequency range $10-100 \mathrm{kHz}$ (e.g. Koerner et al., 1981; Michlmayr and Or, 2014; Michlmayr et al., 2013; Naderi-Boldaji et al., 2017; Smith et al., 2019a, 2019b). In addition, research by Lin et al. (2019) concluded that particle microcracking and crushing mechanisms generate higherfrequency $\mathrm{AE}(>100 \mathrm{kHz})$ than particle interaction mechanisms such as friction and rearrangement (typically $<100 \mathrm{kHz}$ ).

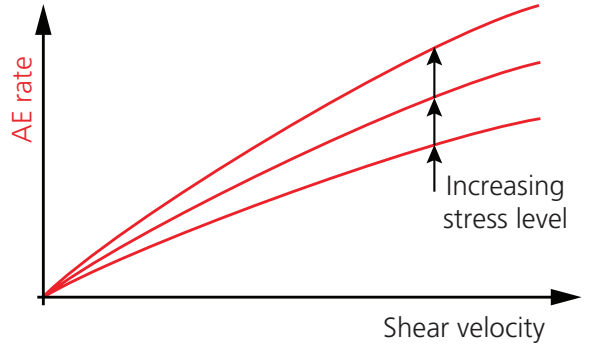

(a)

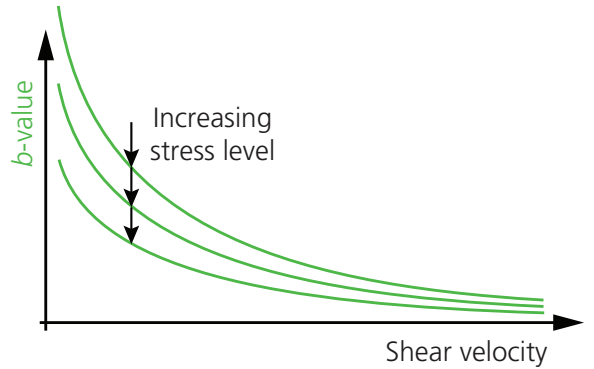

(b)

Figure 6. Illustrative, idealised AE trends from direct-shear tests performed on sand/steel interfaces (from Smith et al. (2019b)): (a) AE rate plotted against shearing velocity; (b) $b$-value plotted against shearing velocity 

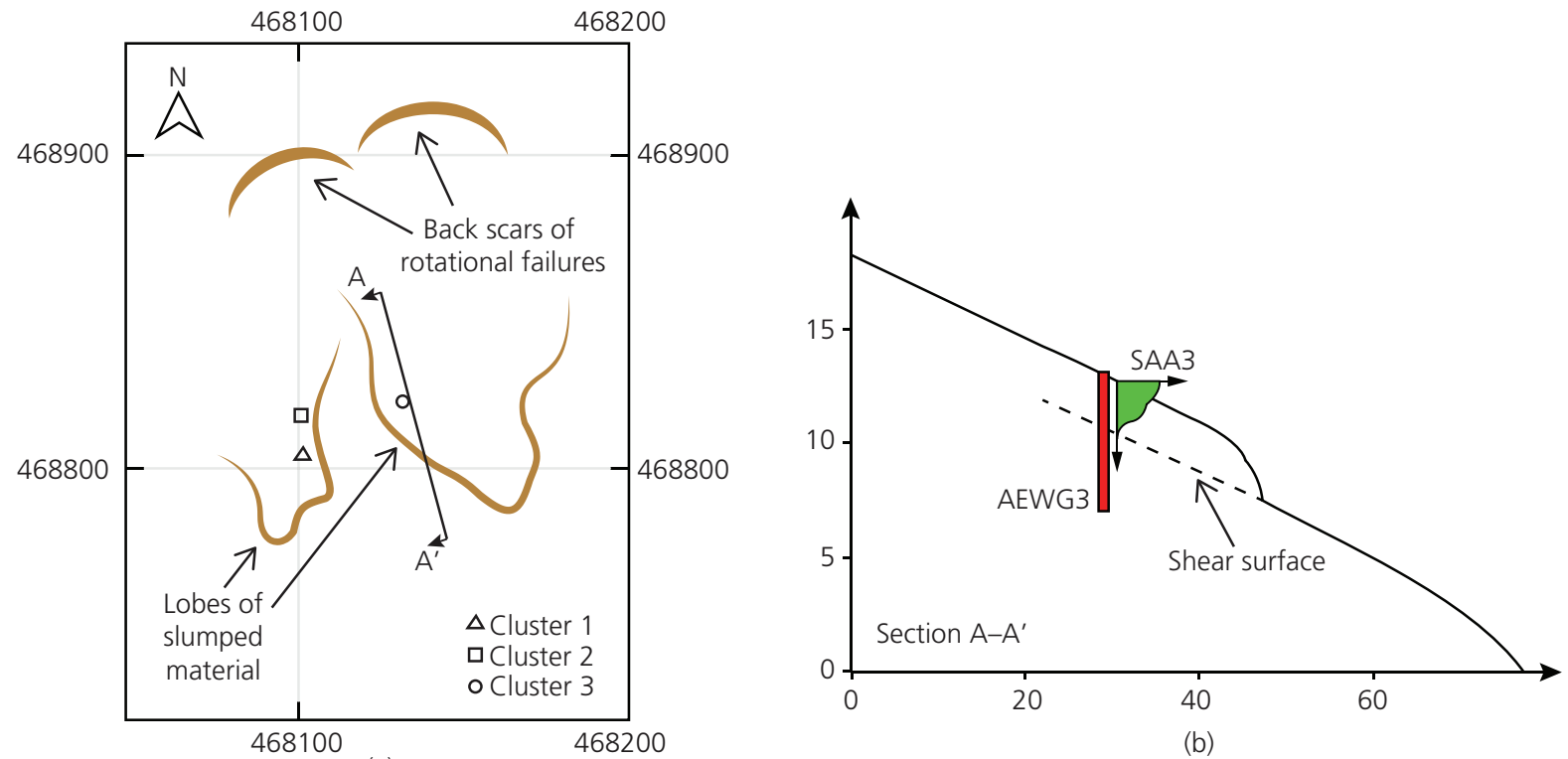

(a)

(b)

Figure 7. Hollin Hill landslide: (a) site plan with instrumentation clusters highlighted (UK Ordnance Survey grid reference system); (b) crosssection through the eastern lobe at instrumentation cluster 3 with exaggerated SAA3 data showing the depth to the shear surface (crosssection axes in metres) (modified from Smith et al. (2014))

These recent research findings, in conjunction with the $\mathrm{AE}$ attenuation studies, are important, as they inform the design of AE-monitoring systems for field use including selection of optimum monitoring frequency, spacing of sensors, $\mathrm{AE}$ characteristics of soil states and trends required to extract information and knowledge of spatial and temporal behaviour.

\section{Example applications of AE monitoring of geotechnical systems}

\subsection{Slope stability}

Extensive field trials and large-scale laboratory experiments of AE monitoring using active waveguides (i.e. steel pipes installed in boreholes with noisy coarse-grained soil surround, Figure 2) installed in slopes have produced a significant body of evidence showing that generated $\mathrm{AE}$ rates are proportional to the rate of slope movement (Berg et al., 2018; Dixon et al., 2015a, 2015b, 2018; Smith and Dixon, 2015; Smith et al., 2014, 2017a). As an example, continuous $\mathrm{AE}$ and displacement measurements were obtained from a reactivated landslide at Hollin Hill (Figure 7) in North Yorkshire, UK. The slope moves periodically due to transient elevations in pore-water pressures. The measurements presented in Figure 8 are taken from cluster 3; AEWG3 is the active waveguide (50 mm dia. steel tube with $3 \mathrm{~mm}$ wall thickness, nominal $10 \mathrm{~mm}$ angular gravel backfill), and SAA3 is the adjacent ShapeAccelArray in-place inclinometer system. The displacement measurements were recorded by SAA3 at the $1.5 \mathrm{~m}$ deep shear surface. Figure 8 shows highly comparable behaviour between cumulative $\mathrm{AE}$ and displacement trends for seven cycles of slope movement and evidence that $\mathrm{AE}$ rates are proportional to slope

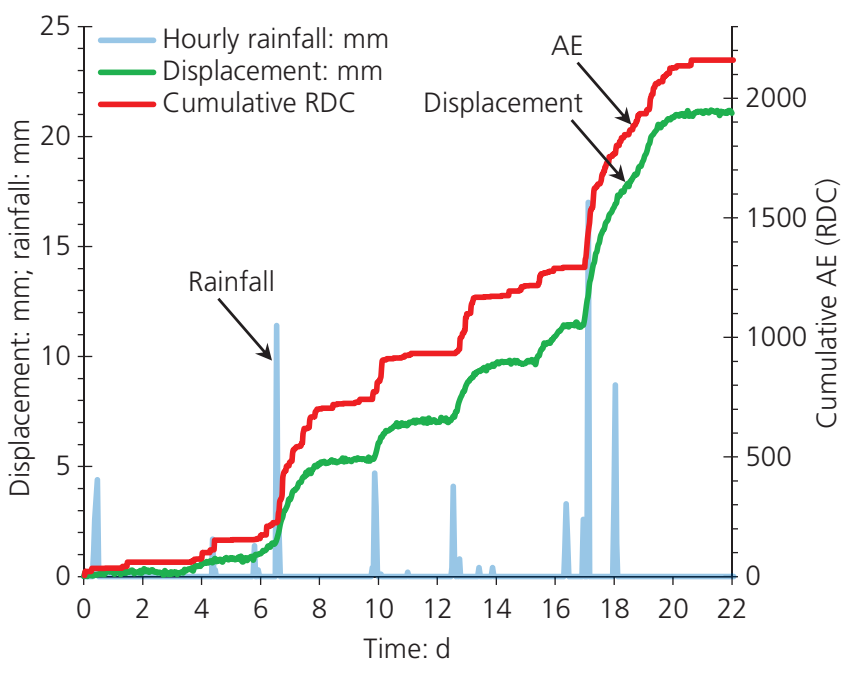

Figure 8. SAA-measured shear surface displacement, cumulative $A E(R D C)$ and hourly rainfall against time for a series of slide events at cluster 3 at Hollin Hill (modified from Smith et al. (2014))

displacement rates. AE rates and velocity are the time derivatives of cumulative AE and displacement, respectively (Smith et al., 2014).

\subsection{Pile foundations}

Small-scale model pile penetration tests (Figure 9(a)) performed by Mao et al. (2018b) demonstrated that measured AE energy was proportional to mobilised penetration resistance. Figure 9(b) shows example results from this study, where a $40 \mathrm{~mm}$ dia. closed-ended pile was pushed into a test box filled with silica sand. The 


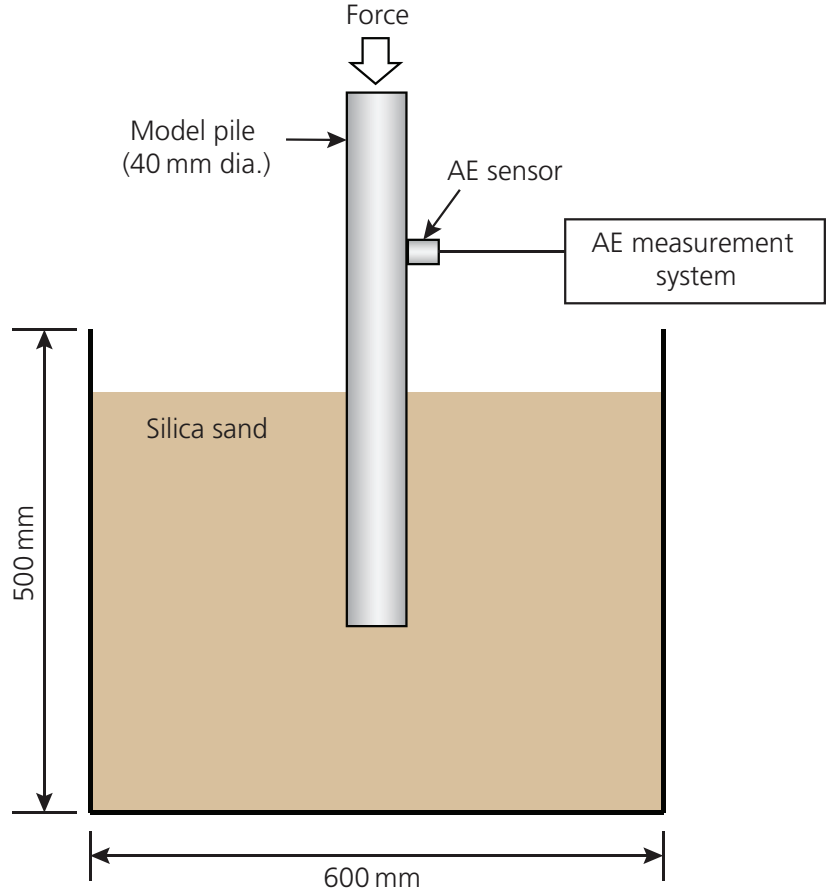

(a)

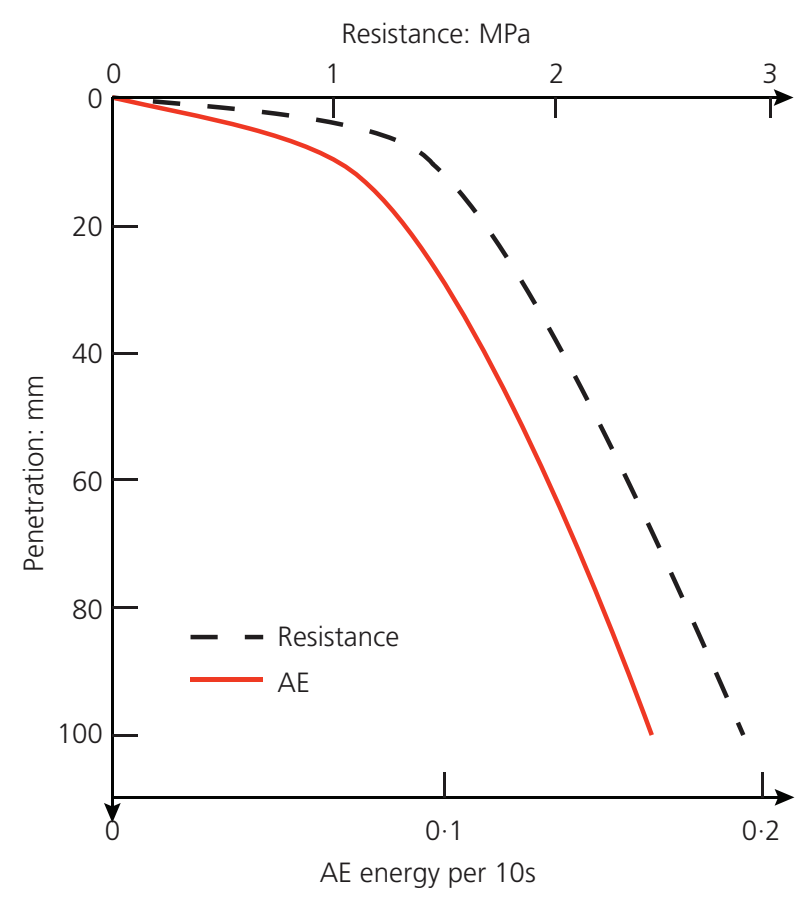

(b)

Figure 9. (a) Schematic diagram of the pile-penetration-testing apparatus detailed in the paper by Mao et al. (2018b); (b) penetration, resistance and AE energy (per $10 \mathrm{~s}$ ) measurements from a pile penetration test performed by Mao et al. (2018b) (modified from Mao et al. (2018b))

interpretation strategy proposed by Mao et al. (2018b) separated $\mathrm{AE}$ above and below $100 \mathrm{kHz}$, which enabled the evolution of particle breakage behaviour beneath the pile tip to be interpreted.

\subsection{Buried pipelines}

Results from a programme of differential ground movement experiments (Figure 10) performed on buried full-scale steel pipes at the Buried Infrastructure Research Facility at Queen's University, Canada, have established that pipe-soil interactiongenerated $\mathrm{AE}$ contains information that can be used to interpret temporal mechanical behaviour (Smith et al., 2019a, 2019c). The steel pipe had an outside diameter of $167 \mathrm{~mm}$ and a wall thickness of $4.5 \mathrm{~mm}$ and was instrumented with $\mathrm{AE}$ sensors, strain gauges, fibre-optic strain sensing and linear potentiometers. Deformation of the soil surface was measured using an automatic total station. The synthetic olivine sand was compacted in layers to a relative density of $85 \%$. Example results from one test performed at a burial depth of $0.6 \mathrm{~m}$ are summarised here. Each test stage comprised $10 \mathrm{~mm}$ of differential floor displacement, giving a total floor displacement of $80 \mathrm{~mm}$.

Figure 11 shows the $\mathrm{AE}$ and vertical downward pipe displacement measurements. The cumulative $\mathrm{AE}$ time series was comparable with the pipe displacement time series (Figure 11(a)). A distinct transition in response takes place in the cumulative $\mathrm{AE}$ against displacement relationship after stage 1 (Figure 11(b)). The insert

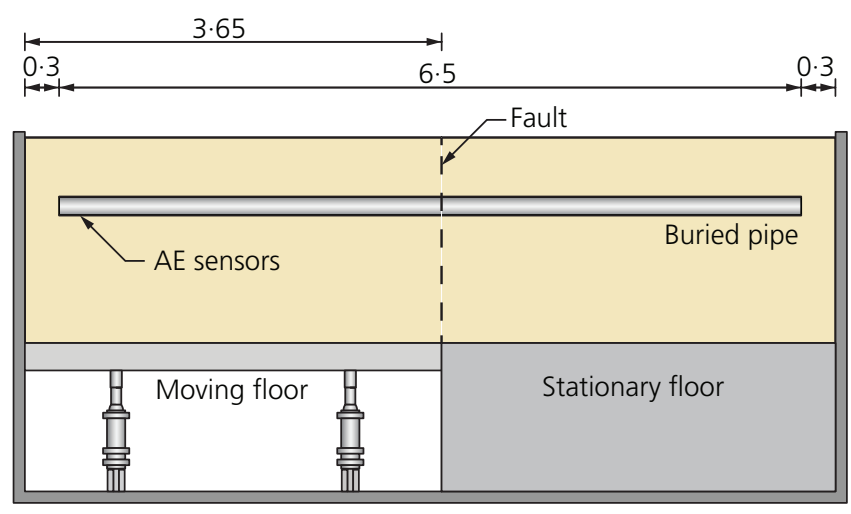

Figure 10. Schematic cross-section of the differential ground movement apparatus with a pipe burial depth of $0.6 \mathrm{~m}$ (modified from Smith et al. (2019a, 2019c))

in Figure 11(b) shows that AE activity initiated during stage 1 after approximately $6 \mathrm{~mm}$ of displacement, corresponding to the fault-rupture shear band intersecting the pipe elevation. A linear regression plotted through the $\mathrm{AE}$ rate against displacement rate relationship (Figure 11(c), average values plotted for each test stage) resulted in an $R^{2}$ value of 0.96 . This establishes the capability of the AE approach to detect accelerating deformation behaviour of a pipe/soil system for use in early warning. 




(a)
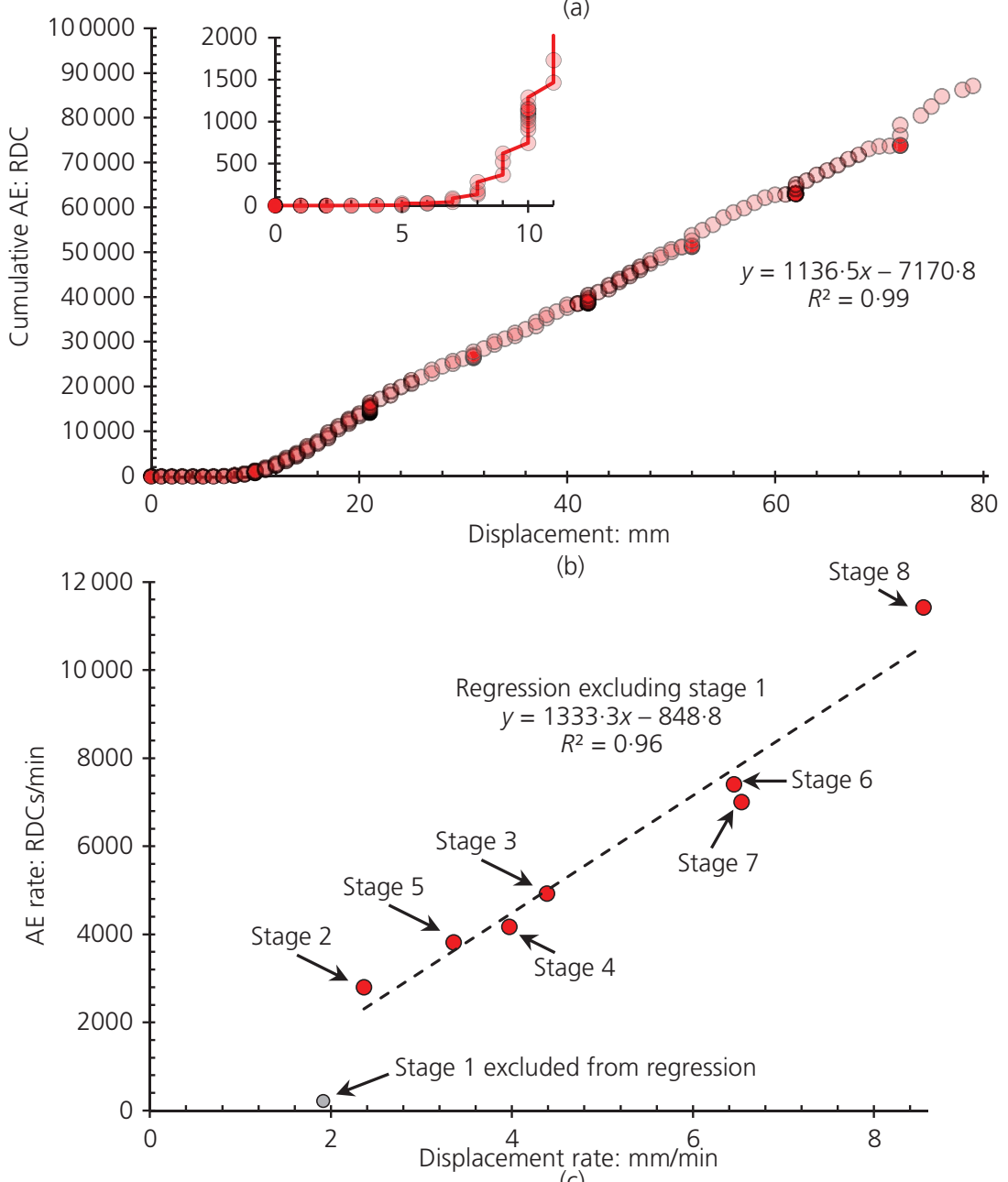

(c)

Figure 11. (a) Cumulative AE and pipe displacement time series; (b) cumulative AE plotted against pipe displacement; (c) AE rate plotted against pipe displacement rate (points represent average values for each test stage) (modified from Smith et al. (2019a, 2019c))

\section{Extracting information and knowledge from AE for decision-making}

Deteriorating geotechnical systems can experience accelerating deformations and strength reductions leading to serviceability and ultimate limit state failures. Detecting the early signs of these processes will enable decision makers to undertake timely preventative measures, reducing damage and potentially saving lives. AE offers a relatively low-cost solution (i.e. an order of magnitude lower cost than that of in-place inclinometer systems) for retrofitting monitoring systems to existing, ageing assets 
Smart Infrastructure and Construction

Volume 171 Issue 4
Listening for deterioration and failure:

towards smart geotechnical

infrastructure

Smith and Dixon because widely spaced sensors can be employed at existing access points to provide continuous, remote and real-time information on deformation behaviour.

AE has become an accepted technology for slope stability monitoring as a result of the following challenges being overcome: $(a)$ the significant attenuation of $\mathrm{AE}$ in soil bodies is addressed by use of waveguides (e.g. coupling sensors to preexisting buried structural elements or installing bespoke waveguide systems); (b) false alarms due to extraneous noise are minimised through use of high monitoring frequencies $(>10 \mathrm{kHz})$; (c) rapid advances in electronics and computing power mean that battery-operated AE measurement devices can be manufactured; and $(d)$ strategies are being developed to identify, quantify and interpret characteristic mechanical behaviour from $\mathrm{AE}$ measurements. However, AE monitoring is yet to become an established practice in other geotechnical domains (e.g. pipelines, foundations, earth dams and retaining structures).

As an example, research has developed an AE landslide earlywarning system, named Slope ALARMS, which is able to provide early detection of progressive failure and quantify slope displacement rates ranging from 0.0001 to more than $400 \mathrm{~mm} / \mathrm{h}$. Performance of the monitoring system has been demonstrated through extensive field trials and large-scale laboratory testing (Berg et al., 2018; Dixon et al., 2015a, 2015b, 2018; Smith and Dixon, 2015; Smith et al., 2014, 2017a). Interpretation strategies for AE slope stability monitoring have been established (e.g. Smith et al., 2017a). Figure 12 shows how slope displacement rates can be quantified from measured $\mathrm{AE}$ rates to provide early warning of accelerating slope movements. A universal

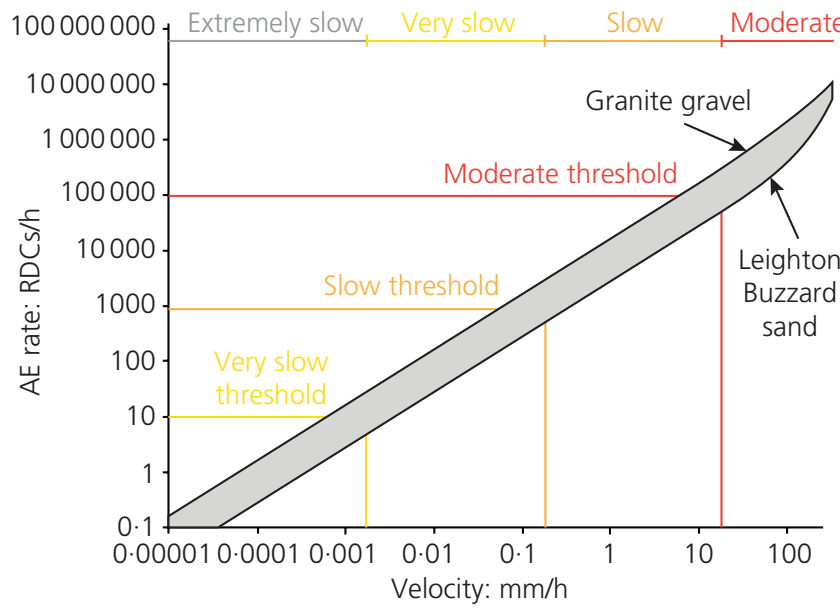

Figure 12. AE rate-velocity calibration relationships derived for a range of active waveguide backfills plotted on log scales with the standard landslide velocity scale (Cruden and Varnes, 1996) superimposed, demonstrating that generic relationships can be obtained for groups of backfills to determine AE rate warning trigger levels based on slope displacement rates (modified from Smith et al. (2017a)) relationship for a range of active waveguide backfill materials is presented, which can be used to quantify changes in displacement rates. The measurements shown in Figure 12 were obtained from a series of large-scale slope failure simulations performed by Smith et al. (2017a). The standard landslide velocity scale is superimposed to facilitate decision-making - for example, alerts are provided when slope movement progresses through 'very slow', 'slow' and 'moderate' thresholds. Accelerating trends whereby the slope progresses through successive displacement rate thresholds warn decision makers of incipient failure.

Smith and Dixon (2019a, 2019b) demonstrated the benefits of using AE to monitor the behaviour of soil bodies in element-scale laboratory experiments, and they proposed a framework to interpret the soil state, including mobilisation of peak shear strength, and to quantify rates of shear strain from $\mathrm{AE}$ measurements (Figure 13). This is particularly valuable for

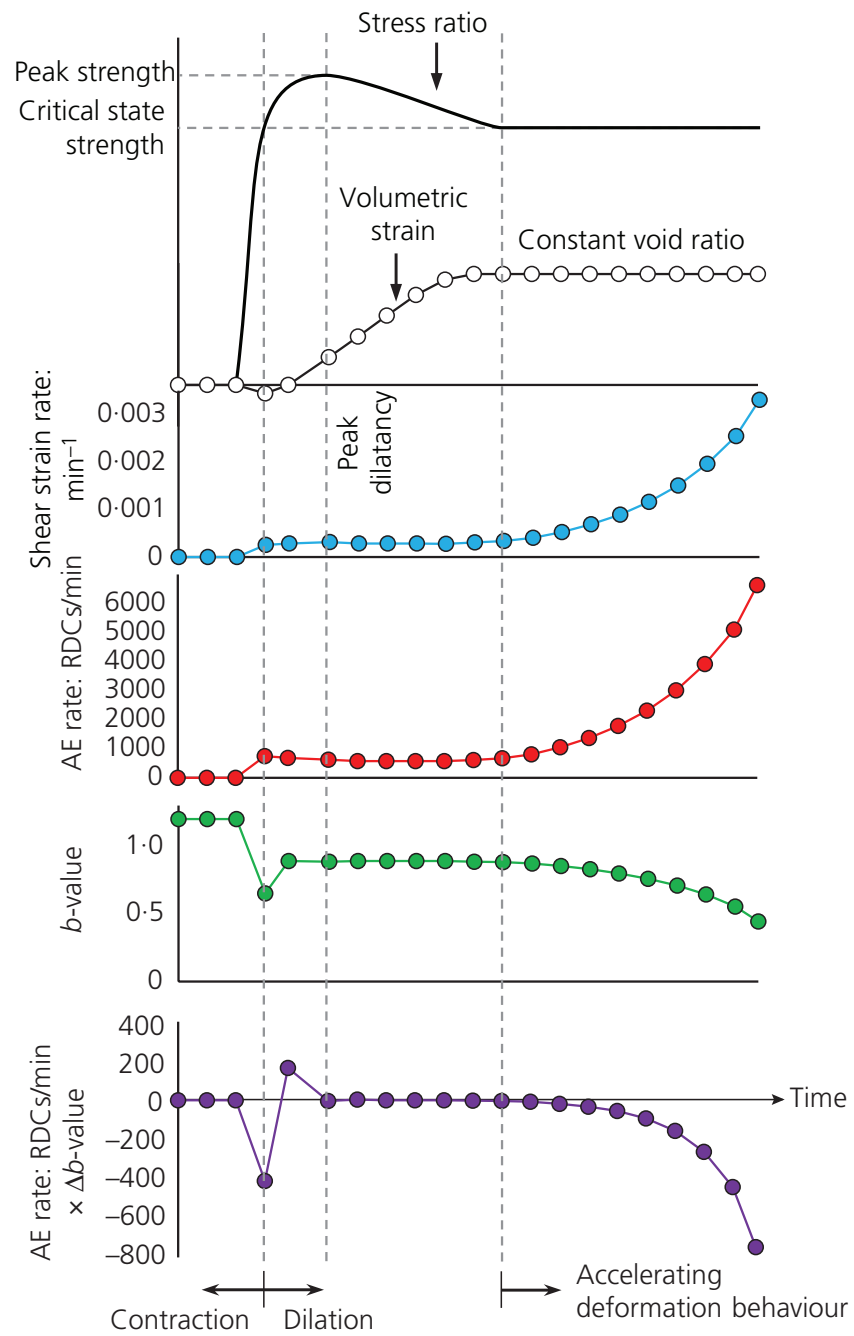

Figure 13. Example use of AE for interpreting pre- and post-peak shear strength mobilisation and accelerating deformation behaviour in dense sand (modified from Smith and Dixon (2019a)) 
Smart Infrastructure and Construction

Volume 171 Issue 4
Listening for deterioration and failure:

towards smart geotechnical

infrastructure

Smith and Dixon monitoring strain-softening geomaterials, where mobilisation of peak shear strength causes shear strains to localise into concentrated shear zones, whereupon an accelerating deformation behaviour ensues, as the soil mass is weaker under the same imposed boundary stresses; this ultimate limit state can have devastating consequences for people and infrastructure. This framework combines RDC and $b$-value measurements to interpret an enhanced level of information about the state and behaviour of the soil compared with monitoring RDC alone. However, challenges still exist to develop $\mathrm{AE}$ interpretation strategies that can be used by decision makers to assess the condition of a wider range of geotechnical assets and hence provide early warning of system failure.

Informed by practice in other smart infrastructure contexts, a conceptual framework for extracting information and knowledge from $\mathrm{AE}$ measurements for use in decision-making is presented in Figure 14. Upward progression in the triangle (Figure 14(a)) decreases the volume of $\mathrm{AE}$ data and increases its value. $\mathrm{AE}$ parameters (time- and/or frequency-domain) are quantified from the raw AE waveform data (Figures 14(b)-14(e)), and derived information is used as input into the interpretation and decisionmaking process (Figures 14(f) and 14(g)). Interpretation and decision-making can use time series analysis to deliver information on rates of change (i.e. accelerating behaviour) or employ artificial intelligence algorithms, such as pattern recognition and deep learning (Figure $14(\mathrm{~g})$ ), trained to output asset condition information or alerts based on a suite of $\mathrm{AE}$ parameter inputs.

\section{Summary}

Geotechnical systems approaching limit states experience accelerating deformations and strength reductions. Detecting the early signs of these processes will enable decision makers to undertake timely preventative measures, reducing damage and saving lives. Smart infrastructure employs sensors and big-data analytics to deliver real-time monitoring of the state and performance of assets, leading to improved decision-making and enhanced service. This will allow a move from scheduled and reactive to predictive and proactive maintenance schemes.

This paper describes a novel approach for smart geotechnical infrastructure that listens to AE generated by geotechnical asset deterioration and failure. The $\mathrm{AE}$ approach addresses the need to retrofit sensors on existing infrastructure, in addition to new build, and which can monitor the state of an asset and detect deterioration mechanisms and their rate of change so that early warnings of limit states can be delivered.

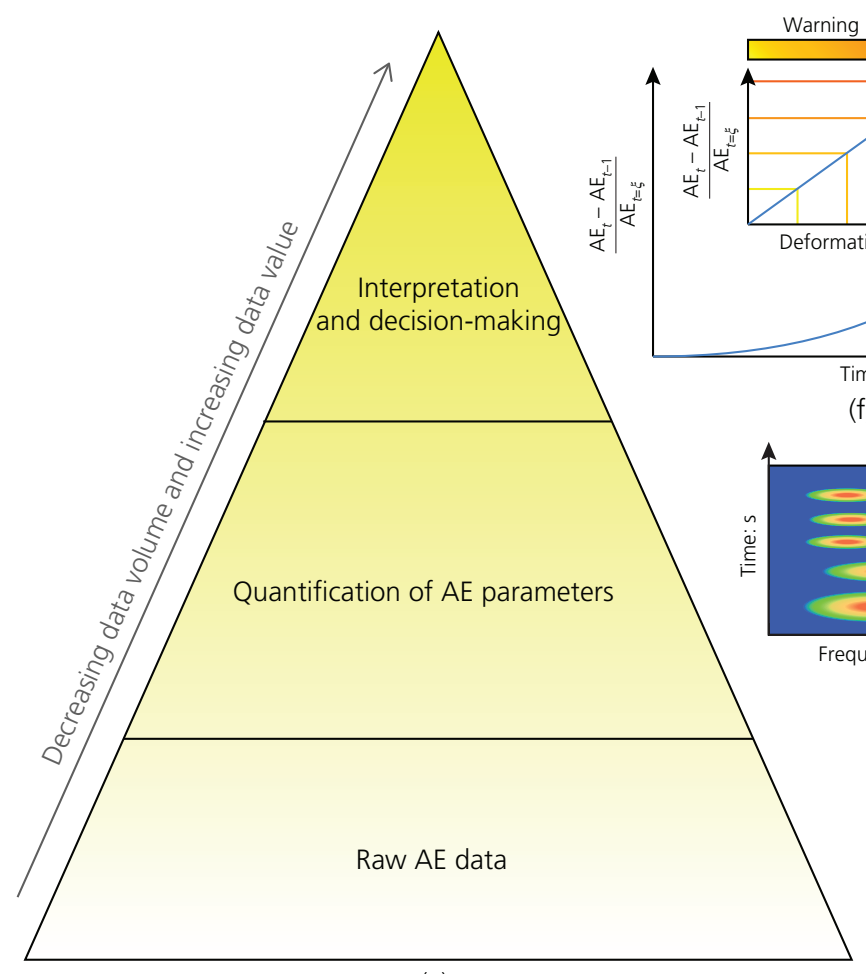

(a)

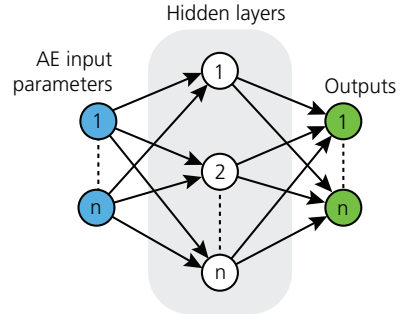

(g)

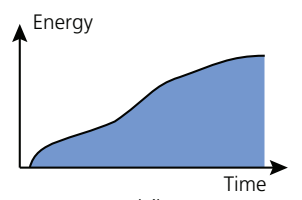

(d)

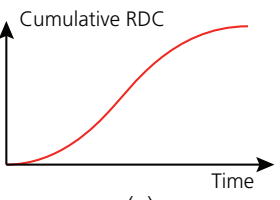

(e)

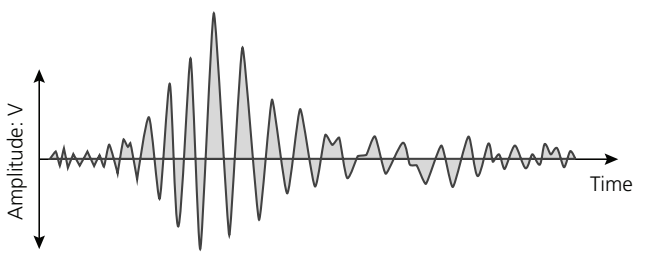

(b)

Figure 14. A conceptual framework for extracting information and knowledge from AE measurements for use in decision-making: (a) progression from raw AE data to interpretation and decision-making (modified from Bowers et al. (2017)); (b) raw AE waveform; (c) joint time-frequency analysis; (d) AE energy; (e) cumulative RDCs; (f) time series analysis for rates of change; (g) deep learning 
Smart Infrastructure and Construction

Volume 171 Issue 4
Listening for deterioration and failure:

towards smart geotechnical

infrastructure

Smith and Dixon
$\mathrm{AE}$ is becoming an accepted monitoring technology for geotechnical applications, and strategies are being developed to identify, quantify and interpret characteristic mechanical behaviour from $\mathrm{AE}$ measurements. Exemplar interpretation strategies developed using element- and large-scale experiments and field trials are presented in the paper. However, challenges still exist to develop widely applicable AE interpretation strategies that can be used by decision makers to deliver information on the condition of a range of geotechnical assets and hence provide early warning of system failure.

The experimental results and $\mathrm{AE}$ attenuation framework described are informing the design of AE-monitoring systems for field use including selection of the optimum monitoring frequency, spacing of sensors, $\mathrm{AE}$ characteristics of soil states and trends required to extract information and knowledge of spatial and temporal behaviour. The conceptual framework presented for extracting knowledge from $\mathrm{AE}$ measurements for use by decision makers illustrates how raw AE measurements can be used in time series analysis and/or artificial intelligence algorithms to interpret geotechnical system state and behaviour.

\section{Acknowledgement}

Alister Smith gratefully acknowledges the support of an Engineering and Physical Sciences Research Council fellowship (Listening to Infrastructure, EP/P012493/1).

\section{REFERENCES}

Alhaddad M, Dewhirst M, Soga K and Devriendt M (2018) A new photogrammetric system for high-precision monitoring of tunnel deformations. Proceedings of the Institution of Civil Engineers Transport 172(2): 81-93, https://doi.org/10.1680/jtran.18.00001.

Beattie AG (1983) Acoustic Emission, Principles and Instrumentation. Sandia National Laboratories, Albuquerque, NM, USA, SAND-822825.

Bennetts J, Webb GT, Vandanega PJ, Denton SR and Loudon N (2018) Using data to explore trends in bridge performance. Proceedings of the Institution of Civil Engineers - Smart Infrastructure and Construction 171(1): 14-28, https://doi.org/10.1680/jsmic.17.00022.

Berg N, Smith A, Russell S et al. (2018) Correlation of acoustic emissions with patterns of movement in an extremely slow-moving landslide at Peace River, Alberta, Canada. Canadian Geotechnical Journal 55(10): 1475-1488.

Bowers K, Buscher V, Dentten R et al. (2017) Smart Infrastructure: Getting More from Strategic Assets. Cambridge Centre for Smart Infrastructure and Construction, Cambridge, UK.

Cheung LLK, Soga K, Bennett PJ et al. (2010) Optical fibre strain measurement for tunnel lining monitoring. Proceedings of the Institution of Civil Engineers - Geotechnical Engineering 163(3): 119-130, https://doi.org/10.1680/geng.2010.163.3.119.

Cruden DM and Varnes DJ (1996) Landslide types and processes. In Landslides: Investigation and Mitigation (Turner AK and Schuster RL (eds)). Transportation Research Board, Washington, DC, USA, Special Report 247, pp. 36-75.

Dixon N, Spriggs MP, Smith A, Meldrum P and Haslam E (2015a) Quantification of reactivated landslide behaviour using acoustic emission monitoring. Landslides 12(3): 549-560.

Dixon N, Smith A, Spriggs M et al. (2015b) Stability monitoring of a rail slope using acoustic emission. Proceedings of the Institution of Civil
Engineers - Geotechnical Engineering 168(5): 373-384, https://doi. org/10.1680/jgeen.14.00152.

Dixon N, Smith A, Flint JA et al. (2018) An acoustic emission landslide early warning system for communities in low-income and middleincome countries. Landslides 15(8): 1631-1644.

Garga VK and Chichibu A (1990) A study of AE parameters and shear strength of sand. Progress in Acoustic Emission V 10th Acoustic Emission Symposium, Sendai, Japan. Japanese Society for NonDestructive Inspection, Tokyo, Japan, vol. 5, pp. 129-136.

Grosse CU and Ohtsu M (eds) (2008) Acoustic Emission Testing. Springer, Berlin, Germany.

Hartmann T (2018) Editorial. Proceedings of the Institution of Civil Engineers - Smart Infrastructure and Construction 171(1): 1-2, https://doi.org/10.1680/jsmic.2018.171.1.1.

Heather-Smith HJ, Smith A, Dixon N, Flint JA and Wordingham J (2018) Monitoring buried infrastructure deformation using acoustic emissions. Proceedings of the 9th European Workshop on Structural Health Monitoring, Manchester, UK.

Hoult N, Bennett PJ, Stoianov I et al. (2009) Wireless sensor networks: creating 'smart infrastructure'. Proceedings of the Institution of Civil Engineers - Civil Engineering 162(3): 136-143, https://doi.org/10. 1680/cien.2009.162.3.136.

ICE (Institution of Civil Engineers) (2016) Intelligent Assets for Tomorrow's Infrastructure: Guiding Principles. ICE Publishing, London, UK.

Koerner RM, Lord AE Jr, McCabe WM and Curran JW (1976) Acoustic emission behavior of granular soils. Journal of Geotechnical and Geoenvironmental Engineering 102(7): 761-773.

Koerner RM, Lord AE Jr and McCabe WM (1978) Acoustic emission monitoring of soil stability. Journal of Geotechnical and Geoenvironmental Engineering 104(5): 571-582.

Koerner RM, McCabe WM and Lord AE (1981) Acoustic emission behavior and monitoring of soils. In Acoustic Emissions in Geotechnical Engineering Practice (Drnevich VP and Gray RE (eds)). ASTM International, West Conshohocken, PA, USA, ASTM STP 750, pp. 93-141

Koerner RM, Lord AE Jr and Deutsch WL (1984) Determination of prestress in granular soils using AE. Journal of Geotechnical Engineering 110(3): 346-358.

Koseki J (2019) Several challenges in advanced laboratory testing of geomaterials with emphasis on unconventional types of liquefaction tests. Geomechanics for Energy and the Environment, https://doi.org/ 10.1016/j.gete.2019.100157.

Lau FDH, Butler LJ, Adams NM, Elshafie MZEB and Girolami MA (2018) Real-time statistical modelling of data generated from self-sensing bridges. Proceedings of the Institution of Civil Engineers - Smart Infrastructure and Construction 171(1): 3-13, https://doi.org/10.1680/ jsmic.17.00023.

Lin W, Liu A and Mao W (2019) Use of acoustic emission to evaluate the micro-mechanical behavior of sands in single particle compression tests. Ultrasonics 99: 105962, https://doi.org/10.1016/j.ultras.2019.105962.

Macciotta R, Hendry M and Martin CD (2016) Developing an early warning system for a very slow landslide based on displacement monitoring. Natural Hazards 81(2): 887-907.

Maji AK, Satpathi D and Kratochvil T (1997) Acoustic emission source location using lamb wave modes. Journal of Engineering Mechanics 123(2): 154-161.

Mao W, Aoyama S, Goto S and Towhata I (2015) Acoustic emission characteristics of subsoil subjected to vertical pile loading in sand. Journal of Applied Geophysics 119: 119-127.

Mao W, Aoyama S, Goto S and Towhata I (2016) Behaviour and frequency characteristics of acoustic emissions from sandy ground under model pile penetration. Near Surface Geophysics 14(6): 515-525.

Mao W, Aoyama S and Towhata I (2018a) Feasibility study of using acoustic emission signals for investigation of pile spacing effect on group pile behaviour. Applied Acoustics 139: 189-202. 
Mao W, Yang Y, Lin W, Aoyama S and Towhata I (2018b) High frequency acoustic emissions observed during model pile penetration in sand and implications for particle breakage behavior. International Journal of Geomechanics 18(11): 04018143.

Mao W, Aoyama S and Towhata I (2019) A study on particle breakage behavior during pile penetration process using acoustic emission source location. Geoscience Frontiers, https://doi.org/10.1016/j.gsf.2019.04.006.

Michlmayr G and Or D (2014) Mechanisms for acoustic emissions generation during granular shearing. Granular Matter 16(5): 627-640.

Michlmayr G, Cohen D and Or D (2013) Shear-induced force fluctuations and acoustic emissions in granular material. Journal of Geophysical Research: Solid Earth 118(12): 6086-6098.

Michlmayr G, Chalari A, Clarke A and Or D (2017) Fiber-optic highresolution acoustic emission (AE) monitoring of slope failure. Landslides 14(3): 1139-1146.

Mitchell RJ and Romeril PM (1984) Acoustic emission distress monitoring in sensitive clay. Canadian Geotechnical Journal 21(1): 176-180.

Mohamad H, Soga K, Pellew A and Bennett PJ (2011) Performance monitoring of a secant-piled wall using distributed fiber optic strain sensing. Journal of Geotechnical and Geoenvironmental Engineering 137(12): 1236-1243.

Naderi-Boldaji M, Bahrami M, Keller T and Or D (2017) Characteristics of acoustic emissions from soil subjected to confined uniaxial compression. Vadose Zone Journal 16(7): 1-12, https://doi.org/10. 2136/vzj2017.02.0049.

Pelecanos L, Soga K, Chunge MPM et al. (2017) Distributed fibre-optic monitoring of an Osterberg-cell pile test in London. Géotechnique Letters 7(2): 152-160, https://doi.org/10.1680/jgele.16.00081.

Pollock AA (1973) Acoustic emission - 2: acoustic emission amplitudes Nondestructive Testing 6(5): 264-269.

Shiotani T and Ohtsu M (1999) Prediction of slope failure based on AE activity. In Acoustic Emission: Standards and Technology Update (Vahaviolos S (ed.)). ASTM International, West Conshohocken, PA, USA, pp. 156-172.

Smith A (2015) Quantification of Slope Deformation Behaviour Using Acoustic Emission Monitoring. PhD thesis, School of Architecture, Building and Civil Engineering, Loughborough University, Loughborough, UK.

Smith A and Dixon N (2015) Quantification of landslide velocity from active waveguide-generated acoustic emission. Canadian Geotechnical Journal 52(4): 413-425.

Smith A and Dixon N (2019a) Acoustic emission behaviour of dense sands Géotechnique 69(12): 1107-1122, https://doi.org/10.1680/jgeot.18.P.209.

Smith A and Dixon N (2019b) Acoustic emission generated by glass beads in compression and shearing. Granular Matter 21(4): 92, https://doi org/10.1007/s10035-019-0944-0.
Smith A, Dixon N, Meldrum P, Haslam E and Chambers J (2014) Acoustic emission monitoring of a soil slope: comparisons with continuous deformation measurements. Géotechnique Letters 4(4): 255-261, https://doi.org/10.1680/geolett.14.00053.

Smith A, Dixon N and Fowmes GJ (2017a) Early detection of first-time slope failures using acoustic emission measurements: large-scale physical modelling. Géotechnique 67(2): 138-152, https://doi.org/10. 1680/jgeot.15.P.200.

Smith A, Dixon N and Fowmes G (2017b) Monitoring buried pipe deformation using acoustic emission: quantification of attenuation. International Journal of Geotechnical Engineering 11(4): 418-430.

Smith A, Moore ID and Dixon N (2019a) Acoustic emission sensing of pipe-soil interaction: full-scale pipelines subjected to differential ground movements. Journal of Geotechnical and Geoenvironmental Engineering 145(12): 04019113.

Smith A, Heather-Smith H, Dixon N, Flint JA and Pennie D (2019b) Acoustic emission generated by granular soil-steel structure interaction. Géotechnique Letters 10(1), https://doi.org/10.1680/jgele. 19.00065 .

Smith A, Moore ID and Dixon N (2019c) Acoustic emission sensing of pipe-soil interaction: development of an early warning system for buried pipe deformation. In International Conference on Smart Infrastructure and Construction 2019 (ICSIC): Driving Data-informed Decision-making (DeJong MJ, Schooling JM and Viggiani GMB (eds)). ICE Publishing, London, UK, pp. 463-468.

Soga K and Schooling J (2016) Infrastructure sensing. Interface Focus 6(4): 20160023, https://doi.org/10.1098/rsfs.2016.0023.

Tanimoto K and Nakamura J (1981) Studies of acoustic emission in soils. In Acoustic Emissions in Geotechnical Engineering Practice (Drnevich VP and Gray RE (eds)). ASTM International, West Conshohocken, PA, USA, ASTM STP 750, pp. 164-173.

Tanimoto K and Tanaka Y (1986) Yielding of soil as determined by acoustic emission. Soils and Foundations 26(3): 69-80.

Uhlemann S, Chambers J, Wilkinson P et al. (2017) Four-dimensional imaging of moisture dynamics during landslide reactivation. Journal of Geophysical Research: Earth Surface 122(1): 398-418.

Weiss A (2009) Smart infrastructure matches supply and demand. Networker 13(3): 18-25.

Wheeler LN, Take WA and Hoult NA (2016) Performance assessment of peat rail subgrade before and after mass stabilization. Canadian Geotechnical Journal 54(5): 674-689.

WHO (World Health Organization) and Unicef JMP (UN Children's Fund Joint Monitoring Programme) (2015) Progress on Drinking Water and Sanitation: 2015 Update and MDG Assessment. WHO Press, Geneva, Switzerland. See http:/www.who.int/water sanitation health/ monitoring/jmp-2015-update/en/ (accessed 15/12/2016).

\section{How can you contribute?}

To discuss this paper, please email up to 500 words to the editor at journals@ice.org.uk. Your contribution will be forwarded to the author(s) for a reply and, if considered appropriate by the editorial board, it will be published as discussion in a future issue of the journal.

Proceedings journals rely entirely on contributions from the civil engineering profession (and allied disciplines). Information about how to submit your paper online is available at www.icevirtuallibrary.com/page/authors, where you will also find detailed author guidelines. 